\title{
Experimental Investigation on Tribological Behaviour of AA6066: HSS-Cu Hybrid Composite in Dry Sliding Condition
}

\author{
T. Sathish $\left(\mathbb{D},{ }^{1}\right.$ L. Natrayan $\mathbb{D}^{1},{ }^{1}$ S. Prasad Jones Christydass, ${ }^{2}$ S. Sivananthan, ${ }^{3}$ \\ R. Kamalakannan, ${ }^{4}$ V. Vijayan $\left(\mathbb{D},{ }^{5}\right.$ and Prabhu Paramasivam (iD) ${ }^{6}$ \\ ${ }^{1}$ Department of Mechanical Engineering, Saveetha School of Engineering, SIMATS, Chennai 602105, Tamilnadu, India \\ ${ }^{2}$ Department of ECE, K. Ramakrishnan College of Technology, Trichy, Tamilnadu, India \\ ${ }^{3}$ Department of Mechanical Engineering, K. Ramakrishnan College of Engineering, Samayapuram, Trichy 621112, \\ Tamilnadu, India \\ ${ }^{4}$ Department of Mechanical Engineering, M. Kumarasamy College of Engineering, Karur, Tamilnadu, India \\ ${ }^{5}$ Department of Mechanical Engineering, K. Ramakrishnan College of Technology, Trichy, Tamilnadu, India \\ ${ }^{6}$ Department of Mechanical Engineering, College of Engineering and Technology, Mettu University, Metu 318, Ethiopia
}

Correspondence should be addressed to T. Sathish; sathish.sailer@gmail.com, L. Natrayan; natrayanphd@gmail.com, and Prabhu Paramasivam; prabhuparamasivam21@gmail.com

Received 8 November 2021; Revised 18 January 2022; Accepted 20 January 2022; Published 3 February 2022

Academic Editor: Temel Varol

Copyright (c) 2022 T. Sathish et al. This is an open access article distributed under the Creative Commons Attribution License, which permits unrestricted use, distribution, and reproduction in any medium, provided the original work is properly cited.

\begin{abstract}
Aluminum is among the most preferred materials based on the desired properties. This investigation focused on to evaluate the wear rate of the AA6066 aluminium alloy composite by using pin-on-disc apparatus. The composites were created with three materials such as AA6066 alloy, high-speed steel, and copper which have a volume percentage variation of $92 \%, 5 \%$, and $3 \%$, respectively. These three parameters were considered for the experimental results of the wear rate such as load applied, sliding speed, and sliding distance. Experimental results of the composites were compared using an applied load of $20 \mathrm{~N}$, a sliding velocity of $3.0 \mathrm{~m} / \mathrm{s}$ and $1800 \mathrm{~m}$ of sliding distance with AAHSSCu reinforced composites offering a minimum wear rate. Similarly, using a $40 \mathrm{~N}$ applied load, the minimum wear rate is obtained. Further increasing the applied load to $60 \mathrm{~N}$ with $600 \mathrm{~m}$ of sliding distance provided a lower wear rate. The various graphical representations such as three-dimensional surface plots, contour plots, and bar charts were used for the experimental results. Wear rate consequences were expressed individually compared based on the considered parameters. Experimental results were having the reliability of nearly ninety-one percentage with only wear rate being focused. Finally, an optimized wear rate is obtained at the sliding distance of $1200 \mathrm{~m}$ with an applied load of $40 \mathrm{~N}$ and a spindle speed of $3 \mathrm{~m} / \mathrm{s}$.
\end{abstract}

\section{Introduction}

In recent days, composites have made major contributions in various regions of the world such as various industrial applications, different home appliance-based products, and different places of usage such as metal matrix composites, reinforcement composites, and fiber composites. In automobile industries, as well as any other industry, the wear rate properties are prepared in every material to increase their life and enhance the wear rate. Revankar et al. [1] absolutely explained about the augmentation of the wear resistance property in the titanium alloy with the aluminium alloy by using the process of ball burnishing. They use ANOVA and ANOM methods for the result comparison with the three different parameters. Various SEM images and comparative images were used to explain the results.

Guleryuz and Cimenoglu [2] described the modification of the surface for the wear resistance capacity with different experimental and result-orientated plots. Borgioli et al. [3] completely explained the various improvement techniques based on the wear resistance through thermal oxidation in the Ti-6Al-4V. Shibe and Chawla [4] undoubtedly reviewed, with the help of different articles from different time periods, about the enhancement of the wear rate through the hard 
facing method. They completely provided the details about the different wear accruing reasons as a mechanism of the different types of wear and the various advantages and disadvantages based on their results. Bhushan and Gupta [5] explained that wear is the removal of the materials when the two different or the same materials are in solid contact together. This material removal rate is also known as the wear rate. There are so many factors that were considered for the wear rate, but decreasing the wear rate leads to an increase of the material life. High-speed steel and copper have higher wear resistance when compared with the aluminium alloy. So, some of the percentage of these materials were added to the composite specimens. Mishra and Srivastava [6] completely explained the wear property analysis in the $\mathrm{Al}$ 6061 aluminium alloy with the silicon carbide composites with different percentages of weights of both particles through the stir casting technique with the traditional standards. They also discussed about the working on the pinon-disk wear tester with a neat sketch for the measurement of the wear rate on the specimens.

Umanath et al. [7] flatteringly discussed about the hybrid MMC participation in the recent reinforced MMC of various materials or alloys to influence both the materials merits and the desired properties of them in a greater manner. Das et al. [8] and Mishra et al. [9] evidently pointed out, commencing their investigation, that the distribution of the reinforcement phase, fraction of volume, positioning, shape, and sizes of composite elements have a considerable impact on the achievable development in the characteristics. Deuis et al. [10] reviewed a number of research articles on the composites of aluminium based on wear with respect to dry sliding in different ways. It gives a clear idea about the wear testing and the methods used for the testing depend on the composites and the various parameters and their influence on the experimental outcomes. Das and Das [11] gave details regarding the composite of the alumina reinforcement with the copper alloy and sand of zircon. They only focused about the abrasive wear-based parametric associate investigation with various diagrammatic representations with the experimental results. Similarly, Yilmaz and Butoz [12] discussed about the abrasive wear with various graphical and experimental results on the aluminium oxide reinforcement with the aluminium alloy composites. Uyyuru et al. [13] mainly focused regarding the wear behavior on the composites of Al-Si-SiCp and the system of automobile pads in the condition of dry sliding. They also expressed the impact of the dry sliding on the composite properties. Acilar and Gul [14] explained about the vacuum infiltration procedure to produce the composite and the dry sliding method is used for the experiments on the wear testing of the composites. Umanath et al. [15] clearly expressed the mechanical properties, specifically tensile strength, related investigations were performed with the composites of the aluminium alloy reinforcement by means of the silicon carbides in the same way Singla et al. [16] focused about the wear rate on the same composites. Panwar et al. [17] unobtrusively explained about the importance and the influence of lubrication on the wear testing in the reinforced aluminium alloy composites. Rao and Das [18] expressed the reliability of the wear rate and coefficient by testing on machines for the composites of the aluminium alloy. Sesharao et al. [19] focused on the impact of the sliding distance on the wear rate response for the heattreated aluminium alloy composite materials by the casting method. Wu et al. [20] explained about the impact of the particle sizes used in the composites for the mechanical behaviour. Natrayan et al. [21] reviewed and concluded from the different research articles that stir casting is a suitable method for the aluminium composite. The pin-on-disc is a suitable testing method for the wear rate. The maximum inputs considered for the wear rate testing were load applied, sliding distance, and speed. Guler et al. [22] examined the minimum wear loss by influencing the reinforcement contents of 4 vol.\% graphite and 4 vol.\% alumina presents in the nanocomposites. These reinforcement particles are highly involved and dominant as the wear mechanism. Guler et al. [23] revealed that the higher corrosion resistance is achieved by using a 24 hour powder milling process. When compared to unmilled and milled powder hybrid nanocomposites, the corrosion rate is obtained as 29.068 and 4.033 mpy, respectively.

Metal matrix composites are termed as reinforcement of different materials into the base material for enhancing the strength of the base material. Normally, the base material is softer than the reinforcement material. This experimental work considered the base material of AA6066 aluminium alloy with reinforced particles of high-speed steel and copper. The various compositions of the AA6066 aluminium alloy with copper and high-speed steel were created. The wear rate of the composite specimens was measured by a wear tester such as the pin-on-disk method [24]. Similarly, the wear rate of the pure AA6066 alloy specimens was identified with the same experimental arrangement. Then, the comparison with both pure alloy and composite specimens was created to realize the impact of the composite and suitable machining parameters for the desired wear rate.

\section{Experimental Procedure}

$\mathrm{Al} 6066$ has the compositions of $0.9-1.8 \%$ of silicon, 0.8 to $1.4 \%$ of magnesium, $0.7-1.2 \%$ of copper, $0.6-1.1 \%$ of manganese chromium have $0.4 \%$, and the remaining was accompanied by pure aluminium alloy [25]. The AA6066 aluminium alloy was used as the microparticles. Similarly, the high-speed steel and the copper material were also used as the microparticles from the market. The taken materials were tested for the initial parameters of the material like microscopic testing for the material confirmation. Then, the particles were mixed in the propositions of volume as ninety-two percentage of the pure aluminium alloy of AA6066 with five percentage of high-speed steel and three percentage of copper.

The stir casting process is considered for this experimental work to prepare the hybrid composites. The base material and the reinforced particles are taken at different weight percentages (92\% of AA6066, 5\% of HSS, and 3\% of $\mathrm{Cu}$ ) and preheated in the furnace. Furthermore, the preheated reinforced particles are poured into the base material and maintained at $400 \mathrm{rpm}$ of stirring speed to 
achieve uniform mixing. Finally, the mixed molten material is poured into the selected die and given some time for cooling.

The specimen has a $20 \mathrm{~mm}$ diameter and a length of $110 \mathrm{~mm}$. Similarly, the pure AA6066 alloy specimen was also prepared using the same method and same dimensions of the composite specimen preparation for the comparison perseverance [26-28].

The specimens were collected and cleaned manually, and then the specimens were visually inspected. The damaged and cracked specimens were rejected, and the specimens with a clear surface and without defects were selected for the investigation [29-31]. Then, the prepared composite specimen was named as AAHSS $\mathrm{Cu}$ based on the combinations of all the materials used in the composite. The pure AA6066 aluminium alloy specimen was mentioned as AA based on the material available on the composite. This flow of specimen preparation and testing is mentioned in Figure 1(a) as a flow chart. Then, the composite material and the pure aluminium material were tested in the traditional wear testing method as pin-on-disc, as referred to by the various references with high accuracy [32].

Specifications of the pin-on-disc equipment used are shown in Figure 1(b), in which the disc is $8 \mathrm{~mm}$ thick and $165 \mathrm{~mm}$ in diameter, 10 to $200 \mathrm{~N}$ of applied load range, 200 to $2000 \mathrm{rpm}$ of rotation speed, and up to $2000 \mu \mathrm{m}$ of wear measurement range with the lever system for the load. Initially, the AA6066 specimen is taken, and the weight is measured before the starting the experiment. Then, the specimen is fixed in the holder of the pin to strengthen the disc. Then, the load is applied on the load pan. The sliding distance is fixed by the adjustable sliding distance arrangement in the middle of the equipment. The sliding speed can be fixed using the digital meter. The time taken for the setup is fixed at 360 seconds for all the experiments by the timer.

There are three different parameters that were considered for the investigational comparison such as sliding distance, load applied, and the speed of sliding, as mentioned in Table 1. The applied load started from $20 \mathrm{~N}$ with a $20 \mathrm{~N}$ incremental value up to $60 \mathrm{~N}$, the sliding distance started from $600 \mathrm{~m}$ with an incremental value of $600 \mathrm{~m}$ up to $1800 \mathrm{~m}$, and the speed of sliding started from $1.5 \mathrm{~m} / \mathrm{s}$ with $1.5 \mathrm{~m} / \mathrm{s}$ incremental values. Then, the experiments were conducted, and the corresponding results from the digital output values such as wear rate were taken as per Table 1 and is performed for the AA6066 specimens. Twenty-seven specimens were created and tested under the conditions of these three parameters.

Similarly, the composite specimens of the AAHSSCu composite are taken in the pin holder and kept there to touch the disc. Then, the load is applied on the load pan with variations of $20 \mathrm{~N}, 40 \mathrm{~N}$, and $60 \mathrm{~N}$. Also, the sliding distance can be fixed at $600 \mathrm{~m}, 1200 \mathrm{~m}$, and $1800 \mathrm{~m}$ by the adjustable sliding distance arrangement on the equipment. At last, the sliding speed is given as $1.5 \mathrm{~m} / \mathrm{s}, 3.0 \mathrm{~m} / \mathrm{s}$, and $4.5 \mathrm{~m} / \mathrm{s}$ by the digital input. The time taken for the testing is fixed at 360 seconds. Then, the wear rate of the AAHSSCu composites was measured as per the conditions mentioned in Table 1.

\section{Results and Discussion}

The experimental results from the traditional pin-on-disc method of wear rate were measured carefully and plotted for easy understanding. Figure 2 mentions the bar chart for the applied force of $20 \mathrm{~N}$ for both pure AA specimens and AAHSSCu composite specimens with respect to the three different sliding speeds. Wear rate variations start from a minimum range of $0.000003 \mathrm{~mm}^{3} / \mathrm{Nm}$ and a maximum range of $0.00015 \mathrm{~mm}^{3} / \mathrm{Nm}$ for the sliding distance of 600 to $1800 \mathrm{~m}$. Figure 3 shows the contour plot for the applied force of $20 \mathrm{~N}$ for the pure AA specimens and the AAHSSCu composite specimens with respect to the three different sliding distances of 600 to $1800 \mathrm{~m}$. Wear rate variations start from a minimum range of $0.000003 \mathrm{~mm}^{3} / \mathrm{Nm}$ and a maximum range of $0.00014 \mathrm{~mm}^{3} / \mathrm{Nm}$ for the sliding speeds from $1.5 \mathrm{~m} / \mathrm{s}$ to $4.5 \mathrm{~m} / \mathrm{s}$. The maximum intensity of the wear rate is achieved at the $4.5 \mathrm{~m} / \mathrm{s}$ of spindle speed of the AA specimen when compared to other conditions.

The measured wear rate can be represented as a bar chart with respect to the sliding distance for the applied load of $20 \mathrm{~N}$ for both AA specimens and AAHSSCu with three different spindle speeds were clearly mentioned. The minimum wear rate was achieved at $1800 \mathrm{~m}$ of sliding distance, at $1.5 \mathrm{~m} / \mathrm{s}$ of the sliding speed at $20 \mathrm{~N}$ applied load of the AAHSSCu composite specimen.

For the applied force of $40 \mathrm{~N}$ for both pure AA specimens and AAHSSCu composite specimens with respect to the three diverse sliding speeds as shown in the bar chart in Figure 4 . Wear rate variations start from a minimum range of $0.000002 \mathrm{~mm}^{3} / \mathrm{Nm}$ and a maximum range of 0.00016 to $0.00018 \mathrm{~mm}^{3} / \mathrm{Nm}$ for a sliding distance of 600 to $1800 \mathrm{~m}$. Figure 5 expresses both pure AA specimens and AAHSSCu composite specimens' contour plots for the applied force of $40 \mathrm{~N}$ concerning the three diverse sliding distances of 600 to $1800 \mathrm{~m}$. Wear rate variations started from a minimum range of $0.000003 \mathrm{~mm}^{3} / \mathrm{Nm}$ and a maximum range of $0.00018 \mathrm{~mm}^{3} / \mathrm{Nm}$ for the sliding speeds from $1.5 \mathrm{~m} / \mathrm{s}$ to $4.5 \mathrm{~m} / \mathrm{s}$. The maximum intensity of the wear rate is achieved for the AA specimen at $4.5 \mathrm{~m} / \mathrm{s}$ of spindle speed.

For both AA specimens and AAHSSCu, with three different spindle speed measured, the wear rate can be represented as a bar chart regarding the sliding distance for the applied load of $40 \mathrm{~N}$, as clearly mentioned in Figure 5. The smallest wear rate was accomplished at a sliding distance of $1800 \mathrm{~m}$, at a sliding speed of $1.5 \mathrm{~m} / \mathrm{s}$ at a $40 \mathrm{~N}$ applied load of the AAHSSCu composite specimen.

Figure 6 demonstrates the bar chart for the applied force of $60 \mathrm{~N}$ for both pure AA specimens and AAHSSCu composite specimens with respect to the three different sliding speeds. For the sliding distance of 600 to $1800 \mathrm{~m}$ wear rate variations started from a minimum range of 0 to $0.000005 \mathrm{~mm}^{3} / \mathrm{Nm}$ and a maximum range of 0.00035 to $0.00040 \mathrm{~mm}^{3} / \mathrm{Nm}$. For both pure AA specimens and AAHSSCu composite specimens, with respect to the three different sliding distances of 600 to $1800 \mathrm{~m}$, is represented by the contour plot in Figure 7 for the applied force of $60 \mathrm{~N}$. Wear rate variations started from a minimum range of $0.000003 \mathrm{~mm}^{3} / \mathrm{Nm}$ and a maximum range of 


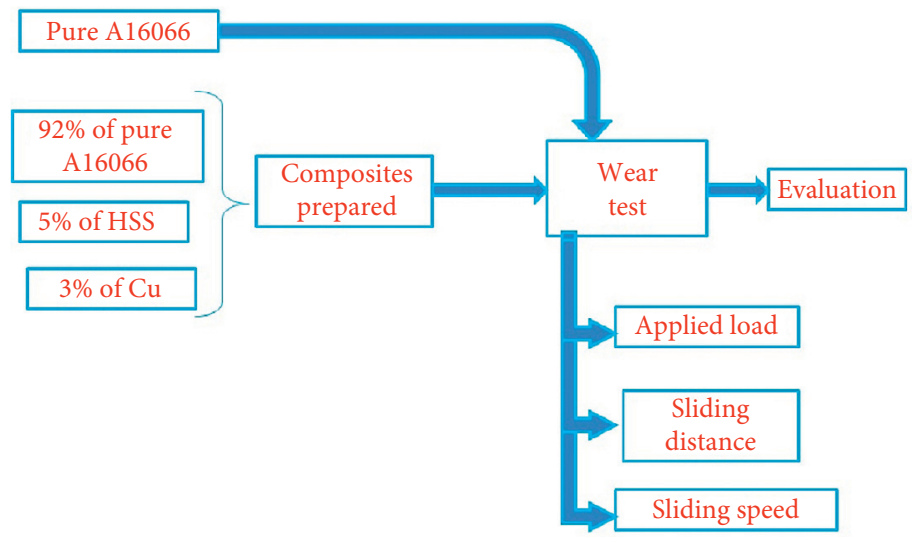

(a)

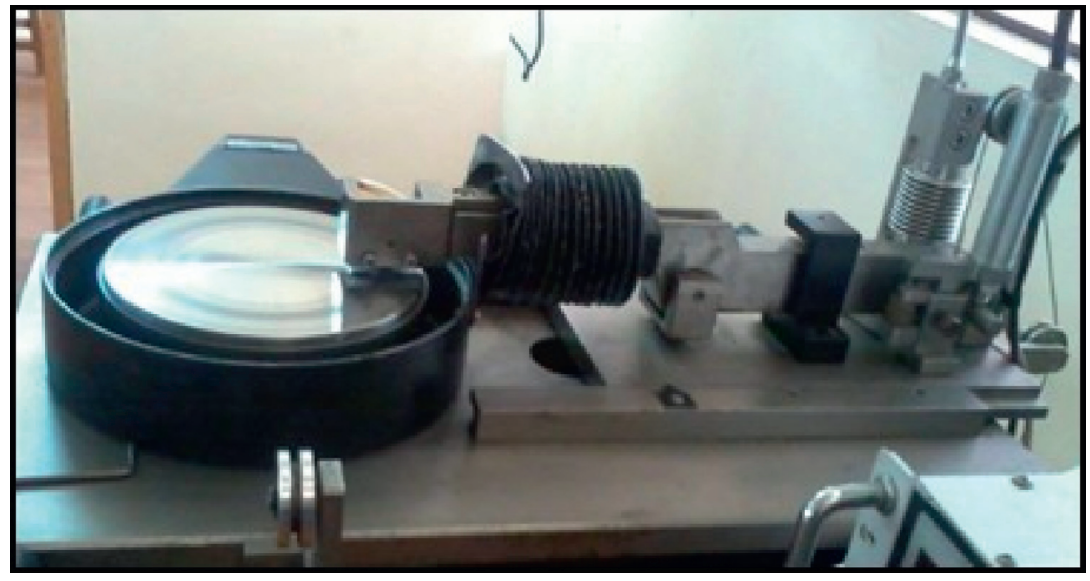

(b)

Figure 1: (a) Experimental methods for the comparison and (b) pin-on-disk wear tester.

TABLE 1: Factors considered for the experiments.

\begin{tabular}{lccc}
\hline Sl. No. & Sliding distance $(\mathrm{m})$ & Applied load $(\mathrm{N})$ & $\begin{array}{c}\text { Sliding speed } \\
(\mathrm{m} / \mathrm{s})\end{array}$ \\
\hline 1 & 600 & 20 & 1.5 \\
2 & 1200 & 40 & 3 \\
3 & 1800 & 60 & 4.5 \\
\hline
\end{tabular}

$0.00010 \mathrm{~mm}^{3} / \mathrm{Nm}$ for the sliding speeds from $1.5 \mathrm{~m} / \mathrm{s}$ to $4.5 \mathrm{~m} / \mathrm{s}$. The maximum intensity of the wear rate is achieved at the $1.5 \mathrm{~m} / \mathrm{s}$ spindle speed of the AAHSSCu composite specimen when compared to other conditions. The smallest wear rate was obtained at the sliding distance of $600 \mathrm{~m}$, at a sliding speed of $1.5 \mathrm{~m} / \mathrm{s}$ at a $60 \mathrm{~N}$ applied load of the AAHSSCu composite specimen.

A minimum sliding speed of $1.5 \mathrm{~m} / \mathrm{s}$ and a maximum sliding distance of $1800 \mathrm{~m}$ offered minimum wear rate. A minimum wear rate was recorded by a homogeneous mixture of base material and reinforced particles through the casting process. In the casting process, the reinforced particles were highly melted and blended uniformly. Even under the influence of the maximum level of load as well as sliding distance, the minimum wear rate was recorded.

Wear rate comparison based on the sliding distances with respect to the spindle speeds for the $20 \mathrm{~N}$ of the

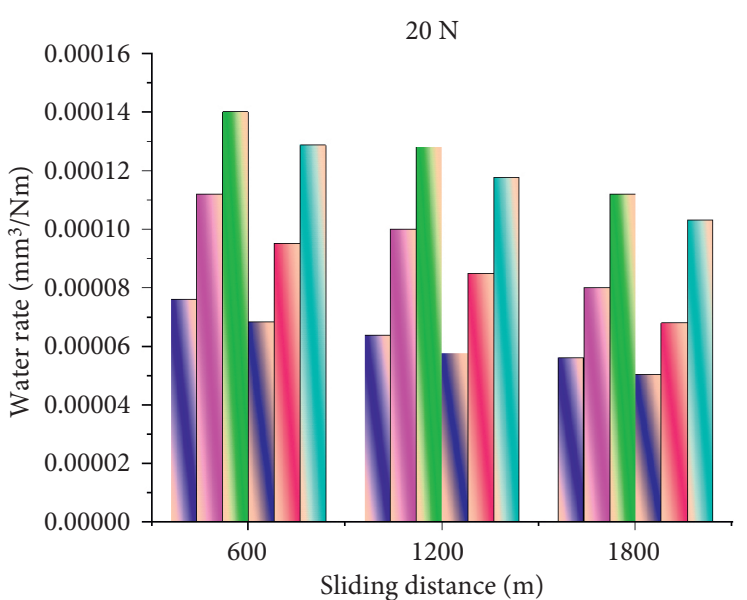

$1.5 \mathrm{~m} / \mathrm{s}(\mathrm{AA})$

$3.0 \mathrm{~m} / \mathrm{s}(\mathrm{AA})$ $4.5 \mathrm{~m} / \mathrm{s}(\mathrm{AA})$

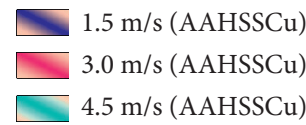

FIgURE 2: Wear rate $\left(\mathrm{mm}^{3} / \mathrm{Nm}\right)$ comparison for a $20 \mathrm{~N}$ applied load impact as a bar chart.

applied load, as shown in Figure 8. The maximum wear rate is reached at $4.5 \mathrm{~m} / \mathrm{s}$ of spindle speed, and the minimum wear rate can be achieved at $1.5 \mathrm{~m} / \mathrm{s}$ of spindle speed 


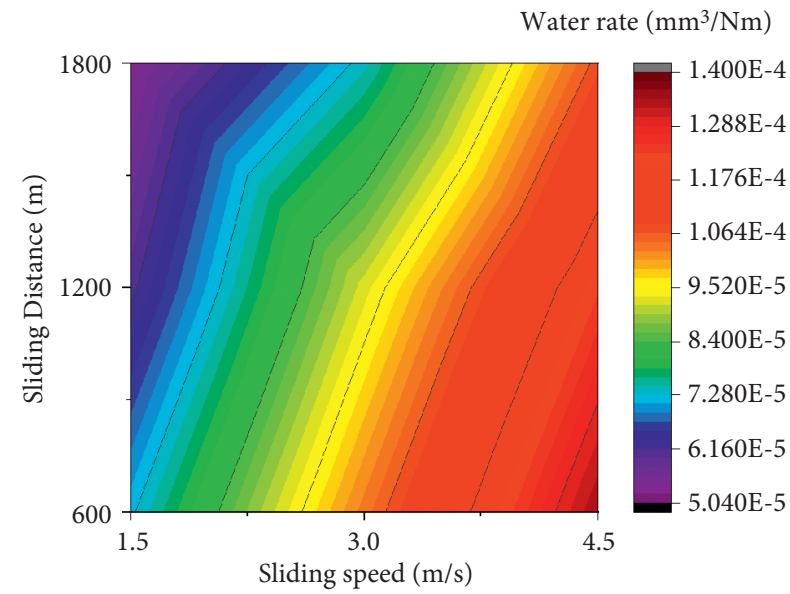

Figure 3: Wear rate $\left(\mathrm{mm}^{3} / \mathrm{Nm}\right)$ comparison for a $20 \mathrm{~N}$ applied load impact as a contour plot.

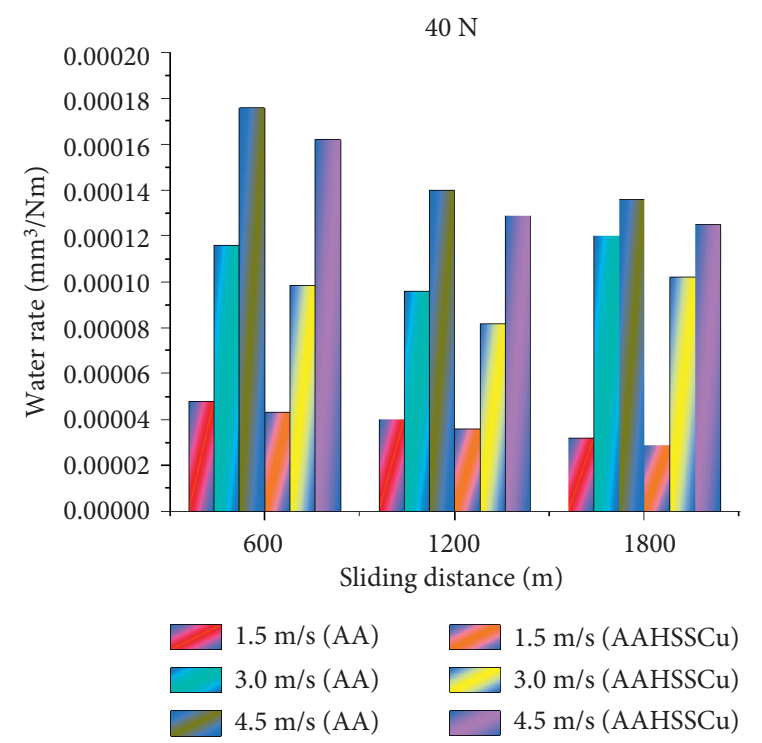

Figure 4: Wear rate $\left(\mathrm{mm}^{3} / \mathrm{Nm}\right)$ comparison for a $40 \mathrm{~N}$ applied load impact as a bar chart.

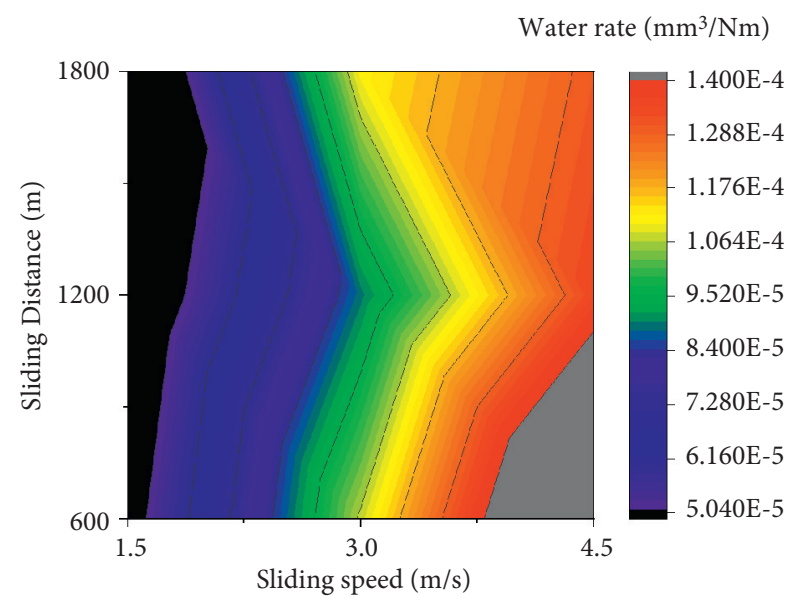

Figure 5: Wear rate $\left(\mathrm{mm}^{3} / \mathrm{Nm}\right)$ comparison for a $40 \mathrm{~N}$ applied load impact as a contour plot.

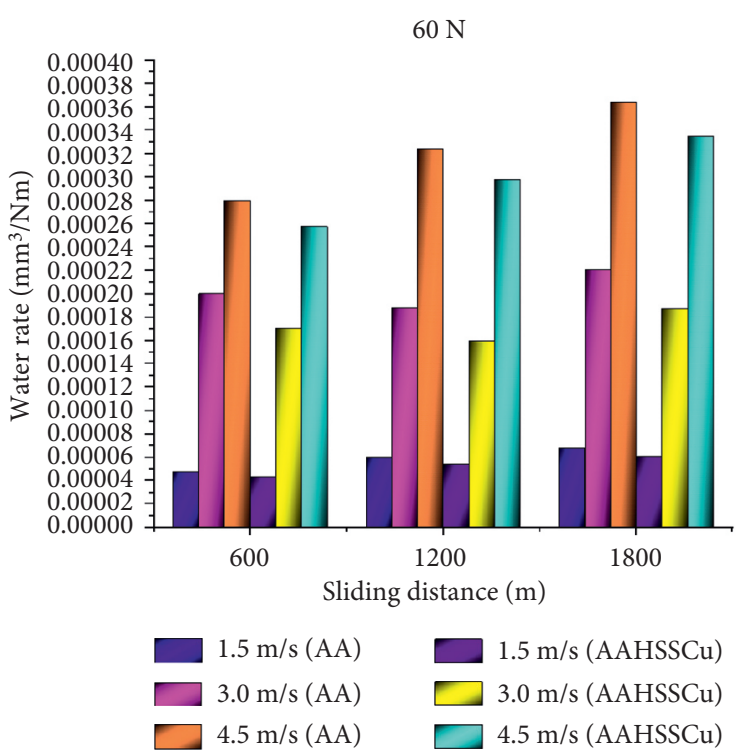

FIgURE 6: Wear rate $\left(\mathrm{mm}^{3} / \mathrm{Nm}\right)$ comparison for a $60 \mathrm{~N}$ applied load impact as a bar chart.

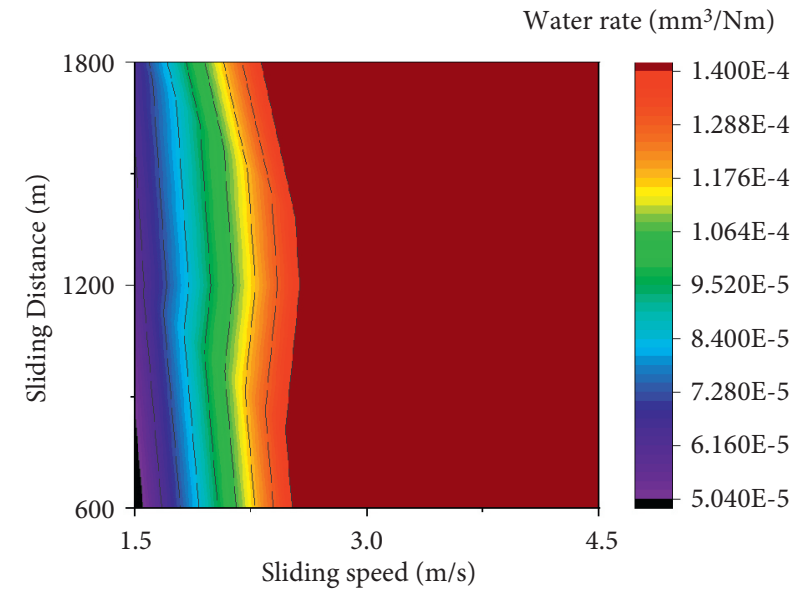

Figure 7: Wear rate $\left(\mathrm{mm}^{3} / \mathrm{Nm}\right)$ comparison for a $60 \mathrm{~N}$ applied load impact as a contour plot.

at a sliding distance of $1800 \mathrm{~m}$ at $20 \mathrm{~N}$ of the applied load. The wear rate evaluation was constructed on the sliding distances with respect to the spindle speeds for the $40 \mathrm{~N}$ of the applied load mentioned in Figure 9. The supreme wear rate is reached at $4.5 \mathrm{~m} / \mathrm{s}$ of spindle speed over $600 \mathrm{~m}$ of sliding distance, and the slightest wear rate can be attained at a sliding distance of $1800 \mathrm{~m}$ with $1.5 \mathrm{~m} / \mathrm{s}$ of spindle speed at $40 \mathrm{~N}$ of the applied load. For the $60 \mathrm{~N}$ of the applied load-based wear rate evaluation based on the sliding distances with respect to the spindle speeds is plotted in Figure $10.4 .5 \mathrm{~m} / \mathrm{s}$ of spindle speed and $1800 \mathrm{~m}$ of sliding distance reached the highest wear rate, and the smallest amount of wear rate can be attained at a sliding distance of $600 \mathrm{~m}$ with $1.5 \mathrm{~m} / \mathrm{s}$ of spindle speed at a $60 \mathrm{~N}$ of the applied load. There is no separate comparison provided for the spindle speed because the abovementioned comparisons have the spindle speed relation included in the plot. All 


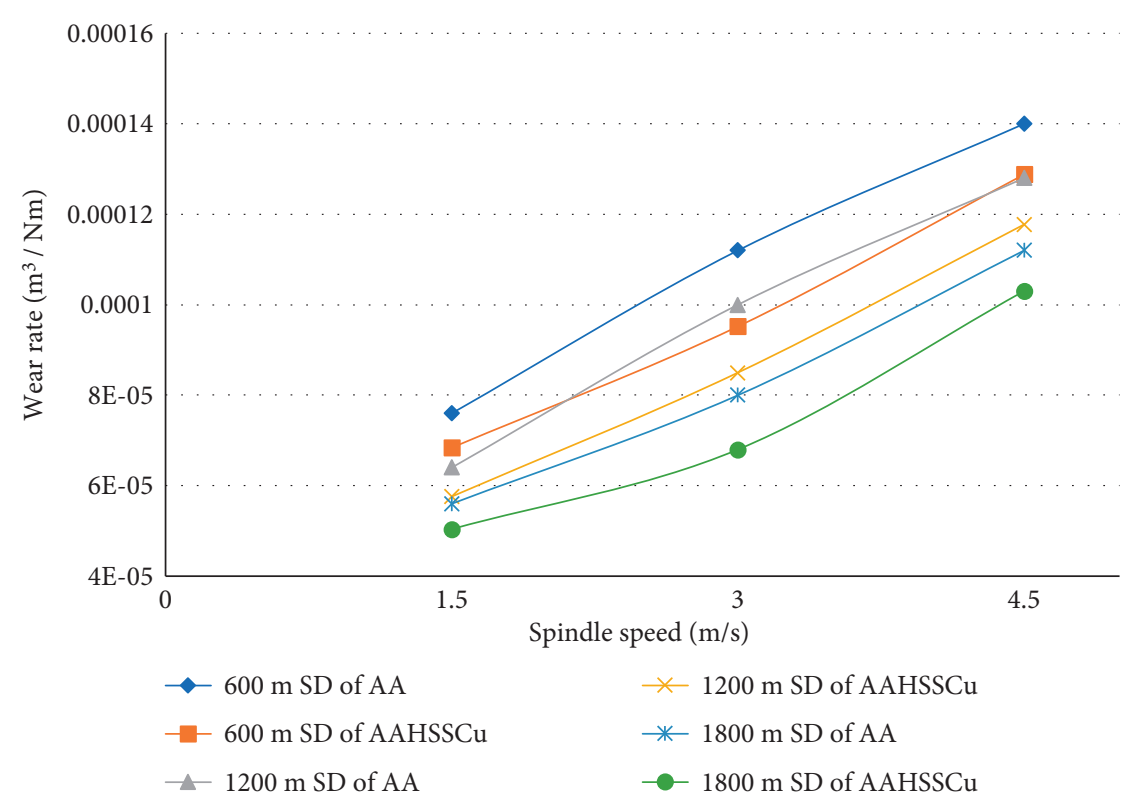

FIgURE 8: Sliding distance comparison on a $20 \mathrm{~N}$ applied load.

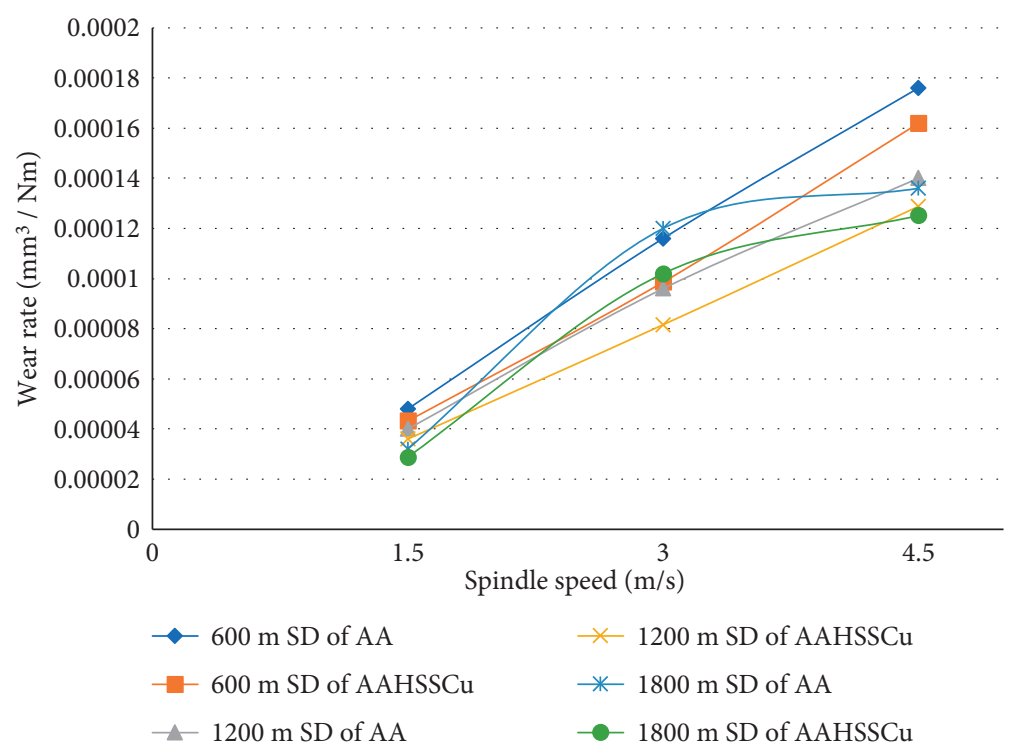

FIgURE 9: Sliding distance comparison on a $40 \mathrm{~N}$ applied load.

these figures show the relation that the wear rate of the composite has the greatest results when compared with the pure aluminium alloy. As the sliding distance increased, the coefficient of friction also increased uniformly. Compared to the hybrid composites, the base alloys possess a higher coefficient of friction. By increasing of the reinforcement percentage to the base material, the coefficient of friction was reduced moderately.
Figure 11 illustrates the SEM image of the wear test specimen under the load of 60 N. Figure 11(a) presents the before wear test specimen, which clearly shows the reinforced particles distributed to the base material such as aluminium alloy. Figure 11(b) shows after wear test specimen where some defects were present on the surface of the specimen such as delamination, groove, and cavity under involving of $60 \mathrm{~N}$ loads. 


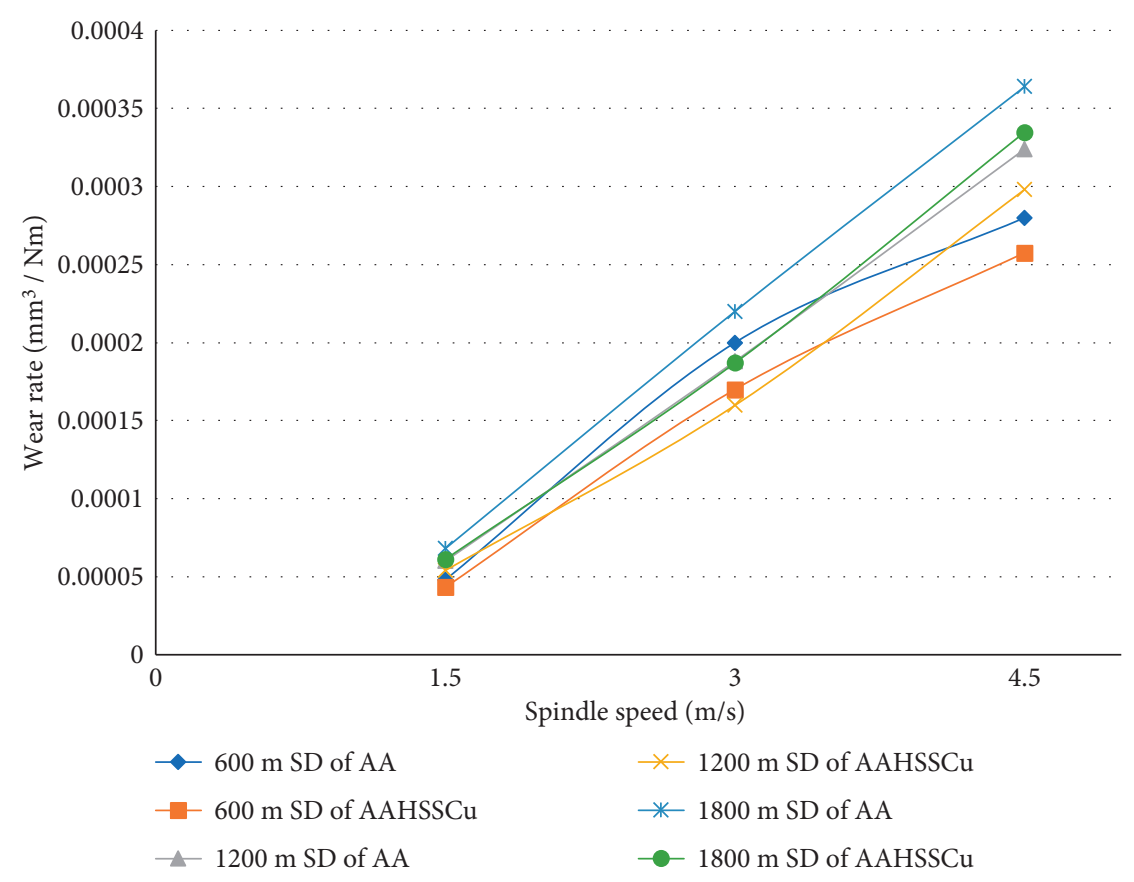

Figure 10: Sliding distance comparison on a $60 \mathrm{~N}$ applied load.

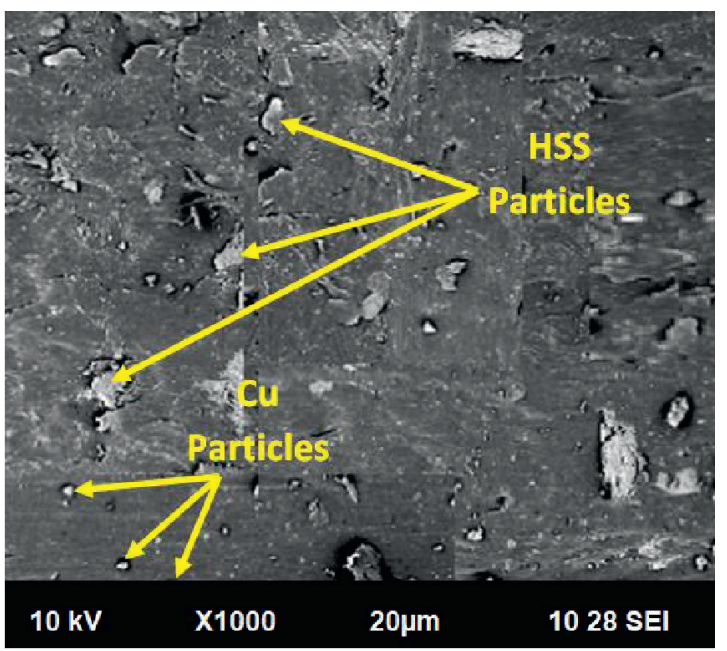

(a)

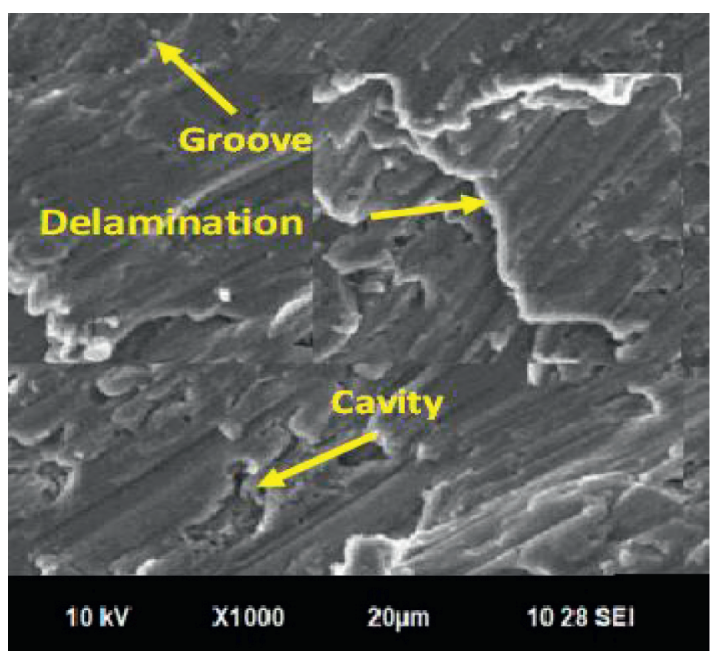

(b)

FIGURE 11: SEM image of the worn out surface for wear specimen: (a) before the wear test specimen and (b) after the wear test on a $60 \mathrm{~N}$ applied load.

\section{Conclusions}

In this experimental study based on wear rate enhancement on high-speed steel and copper, AA6066 aluminium alloy composites were used, which produced the following results as conclusions:

(i) Enhancement of wear rate means reduction in the wear rate not augmentation in wear rate, because it should be reduced to develop the life of the material used product.

(ii) Aluminium alloy with HSS and $\mathrm{Cu}$ composite produced the minimum wear rate when compared with the pure aluminium specimens.

(iii) The aluminium alloy with HSS and $\mathrm{Cu}$ composite with a sliding distance of $1200 \mathrm{~m}$ and an applied load of $40 \mathrm{~N}$ at a spindle speed of $3 \mathrm{~m} / \mathrm{s}$ produced 
the minimum wear rate, so preferable parameters were studied from this investigation.

(iv) The maximum wear rate can be achieved at the AA specimens with $1800 \mathrm{~m}$ of sliding distance at $4.5 \mathrm{~m} / \mathrm{s}$ of spindle speed at the applied load of $60 \mathrm{~N}$.

(v) Wear rate variations are obtained from a minimum of $0.000002 \mathrm{~mm}^{3} / \mathrm{Nm}$ and a maximum of 0.00016 to $0.00018 \mathrm{~mm}^{3} / \mathrm{Nm}$ for the sliding distance of 600 to $1800 \mathrm{~m}$ under $20 \mathrm{~N}$ applied load.

(vi) In applied load, the $40 \mathrm{~N}$ wear rate was varied from a minimum of $0.000002 \mathrm{~mm}^{3} / \mathrm{Nm}$ and a maximum of 0.00016 to $0.00018 \mathrm{~mm}^{3} / \mathrm{Nm}$ for the sliding distance of 600 to $1800 \mathrm{~m}$.

(vii) From an applied load $60 \mathrm{~N}$ and a sliding distance of 600 to $1800 \mathrm{~m}$, the wear rate was varied as a minimum range of 0 to $0.000005 \mathrm{~mm}^{3} / \mathrm{Nm}$ and a maximum range of 0.00035 to $0.00040 \mathrm{~mm}^{3} / \mathrm{Nm}$.

\section{Data Availability}

The data used to support the findings of this study are included within the article. Should further data or information be required, request should be made to the corresponding author upon request.

\section{Disclosure}

It was performed as a part of the Employment of Mettu University, Ethiopia.

\section{Conflicts of Interest}

The authors declare that there are no conflicts of interest regarding the publication of this paper.

\section{Acknowledgments}

The authors thank Saveetha School of Engineering, SIMATS, Chennai, for the technical assistance. The authors appreciate the support from Mettu University, Ethiopia.

\section{References}

[1] G. D. Revankar, R. Shetty, S. S. Rao, and V. N. Gaitonde, "Wear resistance enhancement of titanium alloy (Ti-6Al-4V) by ball burnishing process," Journal of Materials Research and Technology, vol. 6, no. 1, pp. 13-32, 2017.

[2] H. Guleryuz and H. Cimenoglu, "Surface modification of a Ti-6Al-4V alloy by thermal oxidation," Surface and Coatings Technology, vol. 192, no. 2-3, pp. 164-170, 2005.

[3] F. Borgioli, E. Galvanetto, F. Iozzelli, and G. Pradelli, "Improvement of wear resistance of Ti-6Al-4V alloy by means of thermal oxidation," Materials Letters, vol. 59, no. 17, pp. 2159-2162, 2005.

[4] V. Shibe and V. Chawla, "Enhancement in wear resistance by hardfacing: a review," Mechanica Confab, vol. 2, no. 3, pp. 111-122, 2013.
[5] B. Bhushan and B. K. Gupta, Handbook of Tribology: Materials, Coatings, and Surface Treatments, McGraw-Hill, New York, NY, USA, 1991.

[6] A. K. Mishra and R. K. Srivastava, "Wear behaviour of Al6061/SiC metal matrix composites," Journal of the Institution of Engineers (India): Series C, vol. 98, no. 2, pp. 97-103, 2017.

[7] K. Umanath, S. T. Selvamani, and K. Palanikumar, "Friction and wear behaviour of Al6061 alloy Al2O3P) hybrid composites," International Journal of Engineering, Science and Technology, vol. 3, no. 7, pp. 5441-5451, 2011.

[8] S. Das, R. Behera, A. Datta, G. Majumdar, B. Oraon, and G. Sutradhar, "Experimental investigation on the effect of reinforcement particles on the forgeability and the mechanical properties of Al MMCs," Materials Sciences and Applications, vol. 1, pp. 310-331, 2016.

[9] A. K. Mishra, R. Sheokand, and R. K. Srivastava, "Tribological behavior of Al6061/SiC MMCs by Taguchi's technique," International Journal of Scientific and Research Publication, vol. 2, pp. 1-8, 2012.

[10] R. L. Deuis, C. Subramanian, and J. M. Yellup, "Dry sliding wear of aluminium composites-a review," Composites Science and Technology, vol. 57, no. 4, pp. 415-435, 1997.

[11] S. Das and K. Das, "Abrasive wear of zircon sand and alumina reinforced $\mathrm{Al}-4.5 \mathrm{wt} \% \mathrm{Cu}$ alloy matrix composites-a comparative study," Composites Science and Technology, vol. 67, pp. 746-775, 2007.

[12] O. Yilmaz and S. Butoz, "Abrasive wear of $\mathrm{Al}_{2} \mathrm{O}_{3}$ reinforced aluminium based MMCs," Composites Science and Technology, vol. 61, pp. 2381-3239, 2001.

[13] R. K. Uyyuru, M. K. Surappa, and S. Brusethaug, “Tribological behavior of Al-Si-SiCp composites/automobile brake pad system under dry sliding conditions," Tribology International, vol. 40, no. 2, pp. 365-373, 2007.

[14] M. Acilar and F. Gul, "Effect of the applied load, sliding distance and oxidation on the dry sliding wear behaviour of Al-10Si/SiCp composites produced by vacuum infiltration technique," Materials \& Design, vol. 25, no. 3, pp. 209-217, 2004.

[15] K. Umanath, S. T. Selvamani, and K. Natarajan, "Influence of silicon carbide particulate reinforcement on the tensile behaviour of Al6061 alloy composite produced by stir casting method," Proceedings of Manufacturing, vol. 2010, pp. 235324, 2010.

[16] M. Singla, L. Singh, and V. Chawla, "Study of wear properties of Al-SiC composites," Journal of Minerals and Materials Characterization and Engineering, vol. 08, no. 10, pp. 813-821, 2009.

[17] N. Panwar, R. P. Poonia, G. Singh, R. Dabral, and A. Chauhan, "Effect of lubrication on sliding wear of red mud particulate reinforced aluminium alloy 6061," Tribology in industry, vol. 39, no. 3, 2017.

[18] R. N. Rao and S. Das, "Wear coefficient and reliability of sliding wear test procedure for high strength aluminium alloy and composite," Materials \& Design, vol. 31, no. 7, pp. 3227-3233, 2010.

[19] Y. Sesharao, T. Sathish, P. Kumaran et al., "Optimization on operation parameters in reinforced metal matrix of AA6066 composite with HSS and Cu," Advances in Materials Science and Engineering, vol. 2021, Article ID 1609769, 12 pages, 2021.

[20] C. $\mathrm{Wu}, \mathrm{K} . \mathrm{Ma}, \mathrm{J}$. Wu et al., "Influence of particle size and spatial distribution of $\mathrm{B} 4 \mathrm{C}$ reinforcement on the microstructure and mechanical behavior of precipitation strengthened Al alloy matrix composites," Materials Science and Engineering: A, vol. 675, pp. 421-430, 2016. 
[21] L. Natrayan, M. Ravichandran, V. Dhinakaran, P. Sureshkumar, T. Jagadeesha, and W. D. Mammo, "Influence of nano graphite on dry sliding wear behaviour of novel encapsulated squeeze cast $\mathrm{Al}-\mathrm{Cu}-\mathrm{Mg}$ metal matrix composite using artificial neural network," Journal of Nanomaterials, vol. 2021, Article ID 4043196, 14 pages, 2021.

[22] O. Guler, H. Cuvalci, A. Canakci, and M. Celebi, "The effect of nano graphite particle content on the wear behaviour of ZA27 based hybrid composites," Advanced Composites Letters, vol. 26, no. 2, Article ID 096369351702600201, 2017.

[23] O. Guler, M. Celebı, R. Dalmıs, A. Canakci, and H. Cuvalci, "Novel ZA27/B $\mathrm{B}_{4} \mathrm{C} /$ graphite hybrid nanocomposite-bearing materials with enhanced wear and corrosion resistance," Metallurgical and Materials Transactions A, vol. 51, no. 9, pp. 4632-4646, 2020.

[24] P. Mukhopadhyay, "Alloy designation, processing, and use of AA6XXX series aluminium alloys, international scholarly research network," ISRN Metallurgy, vol. 2012, Article ID 165082, 15 pages, 2012.

[25] P. Samal, P. R. Vundavilli, A. Meher, and M. M. Mahapatra, "Recent progress in aluminum metal matrix composites: a review on processing, mechanical and wear properties," Journal of Manufacturing Processes, vol. 59, pp. 131-152, 2020.

[26] A. K. Singh, S. Soni, and R. S. Rana, "A critical review on synthesis of aluminum metallic composites through stir casting: challenges and opportunities," Advanced Engineering Materials, vol. 22, no. 10, Article ID 2000322, 2020.

[27] K. A. Novich, S. V. Pedersen, R. A. Borrelli, R. Christensen, and B. J. Jaques, "Synthesis of boron carbide reinforced aluminum castings through mechanical stir casting," Journal of Composite Materials, vol. 55, no. 16, pp. 2165-2177, 2021.

[28] S. Pan, T. Saso, N. Yu et al., "New study on tribological performance of AA7075- $\mathrm{TiB}_{2}$ nanocomposites," Tribology International, vol. 152, Article ID 106565, 2020.

[29] N. K. Bhoi, H. Singh, and S. Pratap, "Developments in the aluminum metal matrix composites reinforced by micro/nano particles-a review," Journal of Composite Materials, vol. 54, no. 6, pp. 813-833, 2020.

[30] T. B. Rao, "Microstructural Mechanical, and wear properties characterization and strengthening mechanisms of AA7075/ SiCnp composites processed through ultrasonic cavitation assisted stir-casting," Materials Science and Engineering A, vol. 805, Article ID 140553, 2021.

[31] P. Samal, R. K. Mandava, and P. R. Vundavilli, "Dry sliding wear behavior of AA 6082 metal matrix composites reinforced with red mud particles," SN Applied Sciences, vol. 2, no. 2, p. 313, 2020.

[32] K. L. Zheng, X. S. Wei, B. Yan, and P. F. Yan, "Ceramic waste $\mathrm{SiC}$ particle-reinforced $\mathrm{Al}$ matrix composite brake materials with a high friction coefficient," Wear, vol. 458-459, pp. 458-459, 2034. 